\title{
Placenta Previa and Risk of Congenital Malformations among Singleton Births
}

\author{
Asem Anwar Abdo Moussa ${ }^{1}$ MD, Abdel-Sattar Mohammed Ibraheem Farhan ${ }^{1}$ MD, Tamer Mohamed Zalat ${ }^{1,{ }^{*}}$ MSc
}

Obstetrics \&

Gynecology

\section{*Corresponding Author: \\ Tamer Mohamed Zalat \\ tamer.zalat@yahoo.com}

Received for publication January 11,

2020; Accepted January 29, 2020;

Published on line March 11, 2020.

Copyright 2020 The Authors published by Al-Azhar University, Faculty of Medicine, Cairo, Egypt. All rights reserved. This an open-access article distributed under the legal terms, where it is permissible to download and share the work provided it is properly cited.

The work cannot be changed in anyway or used commercially.

doi: 10.21608/aimj.2020.22284.1066

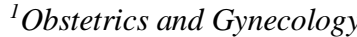

Department, Faculty of Medicine, Al-

Azhar University, Cairo, Egypt

\section{Abstract}

Background: Placenta previa constitutes a major complication in pregnancy, with implantation differences in relation to whether it covers or lies close to the internal os of the cervix.

Objective: The aim of our study was to examine the association between placenta previa and congenital malformations among singleton births.

Materials and methods: In our study, which was conducted on 90223 patients admitted from three tertiary university-affiliated and teaching Hospitals [Bab El-Shaareia University Hospital_Al Mataria Teaching Hospital_El Galaa Teaching Hospital] in the period from 2012 to 2015 their age ranged from $16-47$ years.

Results: In comparison between both groups regarding placenta previa as a risk factor of congenital anomaly we found that $1.7 \%$ of cases with congenital with maternal placenta previa versus $1.2 \%$ with no congenital anomalies and there was statistically significant difference between both groups with $\mathrm{p}$ value 0.042 . With using multivariate logistic regression we found that (age, parity, C.S delivery, fetal sex, DM, HTN, smoking, previous abortion, IUGR with attenuation of placenta previa as independent risk factor so placenta previa considered weak risk factor for congenital anomalies. Our risk estimate was attenuated compared with previous estimates, possibly because of controlling several potential confounders in our analysis that were not examined in previously.

Conclusion: Our study provides further evidence suggesting a weak, but positive association between placenta previa and major congenital malformations, including all structural anomalies, chromosomal defects, and congenital hypothyroidisms, in

Keywords: Placenta Previa, Congenital Malformations, Singleton Births

Disclosure: The authors have no financial interest to declare in relation to the content of this article. The Article Processing Charge was paid for by the authors.

Authorship: All authors have a substantial contributions to the article

\section{INTRODUCTION}

Placenta previa is a condition in which the placenta lies in the lower uterine segment, characterized by abnormal development of placental tissue overlying or in close proximity to the internal os of the cervix. Based on the site of placental implantation in the uterus placenta previa is classified into two main types: (1) major placenta previa, where the placental tissue covers the internal os either completely or partially, and (2) minor placenta previa, where the placenta reaches the internal os, but does not cover it, or it extends into the lower uterine segment, not reaching the internal os ${ }^{1}$.

Women with placenta previa are at a high risk of antepartum bleeding and septicemia during pregnancy $\mathbf{1}$. Ultrasound screening has been immensely useful in detecting placenta previa during the second and third trimesters of pregnancy ${ }^{2}$.

The exact etiology of placenta previa is unknown; however, advanced maternal age (after adjustment for parity), smoking during pregnancy (with a significant dose-response effect), an abnormal shaped uterus, multi-parity (three or more deliveries), multiple pregnancy, prior abortions, prior uterine surgery or caesarean section, uterine abnormalities, and invitro fertilization, have all been associated with an increased risk of placenta previa 3 .
The impact of placenta previa on perinatal mortality, prematurity, and other adverse perinatal outcomes has been well-examined ${ }^{4}$. however, knowledge on its association with major congenital malformations is limited. Few population-based ${ }^{4}$ have reported a positive association between placenta previa and congenital malformations, but the strength of the association has varied widely due to differences in study designs and data sources, sample size, selection criteria, and lack of adequate information to control potential confounders. Placenta previa has been associated with adverse birth outcomes, but its association with congenital malformations is inconclusive ${ }^{6}$.

The objective of this retrospective hospital based cohort study was to examine the association between placenta previa and congenital malformations among singleton births and if it is considered an independent risk factor for congenital malformations.

\section{MATERIALS AND METHODS}

We conducted a retrospective Hospital-based cohort study for all singleton live and stillbirths with congenital malformations born during (2012 to 2015). We linked three registries of three tertiary university-affiliated and teaching Hospitals [ Bab El-Shaareia University Hospital_ Al Mataria Teaching Hospital_El Galaa Teaching Hospital ] using a personal identification number and 
contains information on maternal socio-demographics, reproductive history, pregnancy and delivery characteristics, as well as maternal and infant diagnoses on all live births and stillbirths, neonatal intensive care units data, and cases of elective terminations of pregnancies for severe fetal anomalies, the cause of death Register, with completed and validated data we minimized potential biases.

\section{Patient had been studied and compared as follow:}

Group A: patient with placenta previa delivered baby with and without congenital malformation. Group B: patients without placenta previa and had malformed baby or any baby delivered without malformations.

\section{Risk factors for malformations:}

1. Placenta previa defined as "low-lying placenta covering the internal os of the cervix", represented by International Classification of Diseases (ICD)-10 code 044, and diagnosed by second or third trimester ultrasonography. Did not collect information on specific types of placenta previa.

2. Maternal age (in years) had been examined as a continuous variable.

3. Gestational age (in weeks) was estimated during the first- or second-trimester ultrasonography measurements or from the date of the last menstrual period, and we examined as a continuous variable.

4. Maternal smoking had been reported, and examined indifferent categories (nonsmoker, quitted smoking, and heavy smoking).

5. Socioeconomic status (SES) categorized (high_ middle _low).

6. We also examined presence of preeclampsia, gestational diabetes, and pre-existing diabetes mellitus Information.

7. In vitro fertilization (IVF) included intracytoplasmic sperm injection and frozen embryo transfers.

Sample Size Calculation: The required sample size had been calculated using the IBM $\odot$ SPSS $\odot$ Sample Power@ software version 3 (IBM@ Corp., Armonk, NY, USA). The worldwide incidence of placenta praevia had been estimated at a rate of approximately 5 in 1,000 deliveries ${ }^{7}$. On the other hand, the incidence of major congenital malformations among Egyptian women had been estimated at a rate of 24 per $1000(2.4 \%)$ deliveries ${ }^{8}$.

The data for the current study had been collected from the registries of three tertiary universityaffiliated \& teaching hospitals with an estimated cumulative rate of 70 deliveries per day. The data of patients delivered during a period (from 2012 to 2015) had been retrieved and constituted the data base for the current study. This data base included 96,652 deliveries 6,429 was excluded as a multiple pregnancies $(6.65 \%)$ the included deliveries number was 90,223 . The number of patients with placenta praevia was expected to be approximately 451 patients $(0.05 \%)^{7}$ and the number of babies with major congenital anomalies was expected to be approximately $2,165(2.4 \%)$ babies ${ }^{8}$.

This data base of 90.223 deliveries (89.147 with no placenta praevia and 1.076 with placenta praevia) had a power of $85 \%$ (type II error, 0.15) to reject the null hypothesis that the incidence rate of congenital malformations equals $2.4 \%$ and was identical in patients with or without previa, with a confidence of 95\% (i.e, assuming a type I error of 0.05). The alternative hypothesis was that the incidence rate of congenital malformations equals was not identical in patients with or without praevia and equals $6.2 \%$ or $3.8 \%$ in either group ${ }^{6}$, respectively. These calculations had been carried out using simple logistic regression.

Data had been collected, tabulated, then analyzed using IBM $\odot$ SPSS $\odot$ Statistics version 22 (IBM $\odot$ Corp., Armonk, NY). Normally distributed numerical data had been presented as mean $\pm \mathrm{SD}$, and skewed data as median and interquartile range. Qualitative data had been presented as number and percentage. Comparison of normally distributed numerical data had been done using the unpaired Student $t$ test. Skewed data had been compared using the MannWhitney U test. Categorical data had been compared using the chi-squared test or Fisher's exact test, when appropriate. Multivariable logistic regression had been used to determine independent risk factors for major congenital malformations. A two-sided p-value $<0.05$ had been considered statistically significant.

\section{RESULTS}

This study conducted on 90223 patients admitted from Bab El-Shaareia University Hospital_ Al Mataria Teaching Hospital_El Galaa Teaching Hospital in the period from ( 2012 to 2015)Their age ranged from $16-47$ years with mean \pm SD of 29.63 \pm 5.86 . 


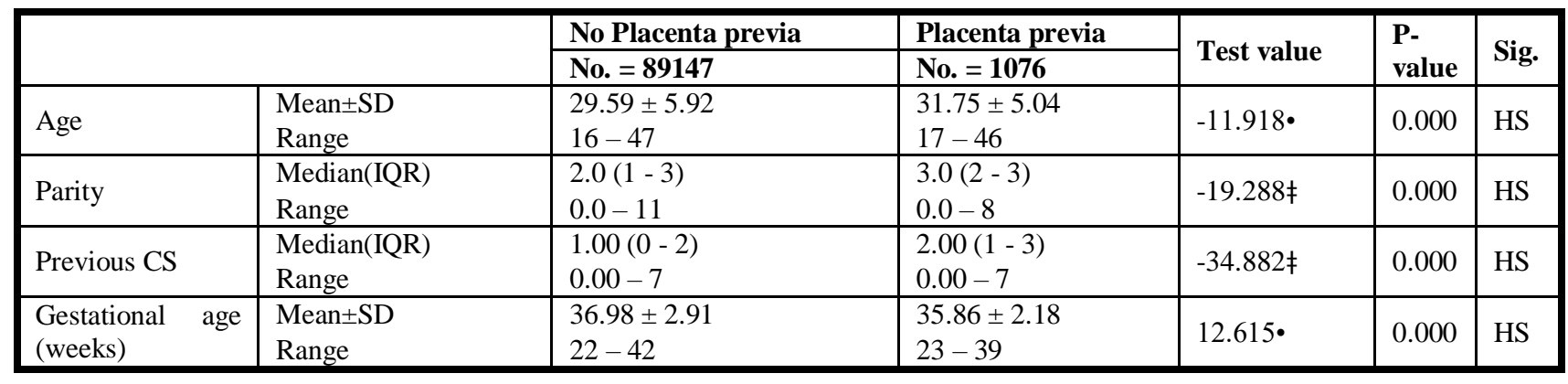

Table 1: Comparison between patients with placenta previa and those without placenta previa regarding age, parity, previous CS and gestational age (weeks) P-value >0.05: Non significant (NS); P-value <0.05: Significant (S); P-value< 0.01: highly significant (HS)

Independent t-test; $\$$ : Mann Whitney test. Table shows that age, number of previous parity and number of previous CS was found higher in patients with placenta previous than those without placenta previa with p-value $<0.001,<0.001$ and $<0.001$ respectively while the table shows also that the gestational age of placenta previa patients was found lower than those of no placenta previa with p-value $<0.001$.

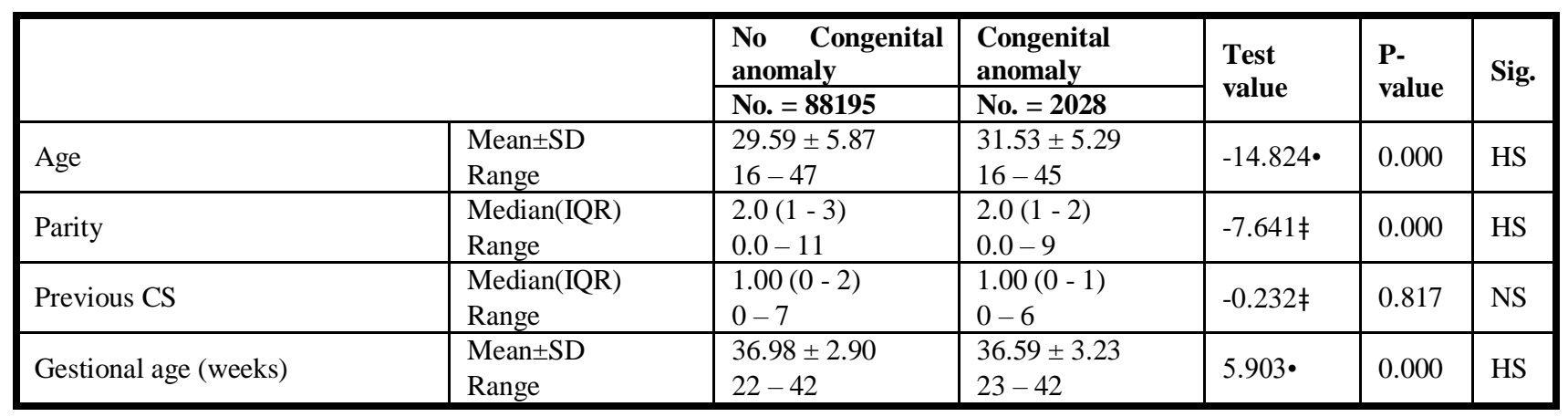

Table 2: Comparison between cases with congenital anomaly and without regarding risk factors and outcome.P-value $>0.05$ : Non significant (NS); P-value $<0.05$ : Significant (S); P-value< 0.01: highly significant (HS)

*:Chi-square test

This table shows comparison between cases with congenital anomaly and without regarding(Age, parity, previous CS, gestational age(weeks)) and there was highly statistically significant difference between both groups regarding Age, parity, gestational age and no statistically significance between both groups regarding previous CS

\begin{tabular}{|c|c|c|c|c|c|c|c|c|}
\hline & & \multicolumn{2}{|c|}{ No Congenital anomaly } & \multicolumn{2}{|c|}{ Congenital anomaly } & \multirow{2}{*}{$\begin{array}{l}\text { Test } \\
\text { value* }\end{array}$} & \multirow{2}{*}{$\begin{array}{l}\text { P- } \\
\text { value }\end{array}$} & \multirow{2}{*}{ Sig. } \\
\hline & & No. & $\%$ & No. & $\%$ & & & \\
\hline D.M & $\begin{array}{l}\text { No } \\
\text { Yes }\end{array}$ & $\begin{array}{l}82917 \\
5278\end{array}$ & $\begin{array}{l}94.0 \% \\
6.0 \%\end{array}$ & $\begin{array}{l}1830 \\
198\end{array}$ & $\begin{array}{l}90.2 \% \\
9.8 \%\end{array}$ & 49.655 & 0.000 & HS \\
\hline Placenta previa & $\begin{array}{l}\text { No } \\
\text { Yes }\end{array}$ & $\begin{array}{l}87153 \\
1042\end{array}$ & $\begin{array}{l}98.8 \% \\
1.2 \%\end{array}$ & $\begin{array}{l}1994 \\
34\end{array}$ & $\begin{array}{l}98.3 \% \\
1.7 \%\end{array}$ & 4.1223 & 0.042 & S \\
\hline Smoking & $\begin{array}{l}\text { No } \\
\text { Yes }\end{array}$ & $\begin{array}{l}87612 \\
583\end{array}$ & $\begin{array}{l}99.3 \% \\
0.7 \%\end{array}$ & $\begin{array}{l}2001 \\
27\end{array}$ & $\begin{array}{l}98.7 \% \\
1.3 \%\end{array}$ & 13.265 & 0.000 & HS \\
\hline IVF/ICSI & $\begin{array}{l}\text { No } \\
\text { Yes }\end{array}$ & $\begin{array}{l}87620 \\
575 \\
\end{array}$ & $\begin{array}{l}99.3 \% \\
0.7 \% \\
\end{array}$ & $\begin{array}{l}1998 \\
30 \\
\end{array}$ & $\begin{array}{l}98.5 \% \\
1.5 \% \\
\end{array}$ & 20.372 & 0.000 & HS \\
\hline $\begin{array}{l}\text { Socioeconomic } \\
\text { standard }\end{array}$ & $\begin{array}{l}\text { Low } \\
\text { Middle }\end{array}$ & $\begin{array}{l}41474 \\
46721\end{array}$ & $\begin{array}{l}47.0 \% \\
53.0 \%\end{array}$ & $\begin{array}{l}920 \\
1108\end{array}$ & $\begin{array}{l}45.4 \% \\
54.6 \%\end{array}$ & 2.194 & 0.139 & NS \\
\hline
\end{tabular}

Table 3: Comparison between no congenital anomaly and congenital anomaly regarding risk factors (D.M, H.N, Smoking, IVF/ICSI, Socioeconomic standard) P-value >0.05: Non significant (NS); P-value <0.05: Significant (S); P-value< 0.01: highly significant (HS)

*:Chi-square test. This table shows comparison between no congenital anomaly and congenital anomaly regarding (D.M, H.N, Smoking, placenta previa, and IVF/ICSI) which was highly statistically significant and socioeconomic standard which was not statistically significant. 



\section{DISCUSSION}

We found that placenta previa during pregnancy being associated with increased risk of congenital malformations in the offspring with other co-factors such as maternal age, parity,diabetes ,smoking IVF.

In our study, which was conducted on 90223 patients admitted from three tertiary university-affiliated or teaching Hospitals [Bab El-Shaareia University Hospital_Al Mataria Teaching Hospital_El Galaa Teaching Hospital] in the period from 2012 to 2015 their age ranged from $16-47$ years with mean \pm SD of $(29.63 \pm 5.86) .89148(98.8 \%)$ were without placenta previa, $1032(1.1 \%)$ with placenta previa and $43(0.05 \%)$ with placenta previa and accreta.

Parity ranged from $\left(\begin{array}{ll}0 & -11\end{array}\right)$ with median of 2. Previous cesarean section in admitted women ranged from (0-7) with median 1 .

In table (1) we made comparison between women who had placenta previa and women who had not according to maternal age, parity, previous c.s and gestational age. In women without placenta previa age ranged from $(16-47)$ with mean \pm SD $(29.59 \pm 5.92)$ and in women with placenta previa age ranged from $(17-46)$ with mean \pm SD $(31.75 \pm$ $5.04)$, parity in women without placenta previa ranged from $(0.0-11)$ with median $2.0(1-3)$ while parity in women with placenta previa ranged from $(0.0-8)$ with median $3.0(2$ - 3), in comparison according to Previous CS women without placenta previa who undergone CS ranged from $(0.00-7)$ with median 1 and with placenta previa with median2.00 (1 3 ). There was highly statistically significant difference between both groups with $p$ value $<0.001$ and this study agree with Kancherla et al. ${ }^{6}$ which was a retrospective populationbased study of all singleton births born at or after 22 weeks of gestation in Finland during 2000 to 2010 who found that $49 \%$ of women had no placenta previa with ages more than 29 years while $57.2 \%$ of them had placenta previa with $\mathrm{p}$ value< 0.001 and placenta previa increase in women with previous CS with percentage of $17.2 \%$ in comparison to 10.5 in women without placenta previa with $\mathrm{p}$ value $<0.001$ and there was no significant difference in parity in both groups.

Our study disagree with Paul et al. ${ }^{9}$ A case control study conducted on Mulago hospital labour suite Participants: Between 15th November 2001 and 30th November 2002 we identified and recruited thirty six parturients with placenta previa who developed severe bleeding and 180 women with normal delivery. This study found no significant difference between both groups according to maternal age with $p$ value 0.06 . also found that parity not found to be risk factors for $\mathrm{pp}$.

In table (1) we found in comparison between women with and without placenta previa that gestational age in case of placenta previa ranged from $(23$ - 39) weeks with Mean $\pm \operatorname{SD}(35.86 \pm 2.18)$, while in cases without previa gestational age ranged from $(22-42)$ weeks with Mean $\pm \operatorname{SD}(36.98 \pm 2.91)$. There was statistically significant difference found between patients with placenta previa and those without placenta previa with $\mathrm{p}$ value<o.oo1. So prematurity increase in presence of placenta previa in accordance with Zlatnik et al. ${ }^{10}$, they conducted a retrospective cohort study of singleton births that occurred between 1976 and 2001, examining outcomes including preterm delivery and perinatal complications. Among the 38 540 women, 230 women had previas $(0.6 \%)$. Compared to controls, pregnancies with previa were significantly associated with preterm delivery prior to 28 weeks $(3.5 \%$ vs. $1.3 \% ; p=0.003), 32$ weeks $(11.7 \%$ vs. $2.5 \% ; p<0.001)$, and 34 weeks $(16.1 \%$ vs. $3.0 \%$; $<<0.001)$ of gestation. Our study also agreed with Kancherla et al. ${ }^{6}$ who found that there was significant difference between gestational age in both groups with $\mathrm{p}$ value $<0.001$. Preterm with placenta previa may be explained by bleeding episodes leading to emergency cesarean section as well as elective cesarean sections contributes to the increased risk of preterm delivery with placenta Previa.

In table (2) in comparison between cases with and without congenital anomalies regarding maternal age we found that cases without congenital anomaly maternal age ranged (16 47) with Mean \pm SD $(29.59 \pm 5.87)$ while in cases with congenital anomaly age ranged $16-45$ with Mean \pm SD31.53 \pm 5.29 and there was statistically significant difference in both groups with $\mathrm{p}$ value 0.000 . Our study agreed with ClearyGoldman et al. ${ }^{11}$ whose study was prospective database from a multicenter investigation of singletons, the FASTER trial, was studied. Subjects were divided into 3 age groups: 1 ) less than 35 years, 2) 35-39 years, and 3) 40 years and older. Multivariable logistic regression analysis was used to assess the effect of age on outcomes after adjusting for race, parity, body mass index, education, marital status, smoking, medical history, use of assisted conception, and patient's study site. And found that increasing age was significantly associated with congenital anomalies (adjOR 1.4 and 1.7). Also our study in accordance with Parmar et al. ${ }^{12}$ whose study was a descriptive, cross-sectional study of newborns and stillborn babies. Total 4210 babies were studied in the neonatal period immediately after birth. Incidence was significantly higher $(6.1 \%)$ in mothers aged $>30$ years as compared to younger age group.

It is well established that advancing maternal age is associated with subfertility, chromosomal abnormalities, and multiple gestation. In patients aged 40 years and older, the higher incidence of antepartum complications such as miscarriage, gestational diabetes, placenta previa, and placental abruption have been documented. The increased incidence of miscarriage is thought to be secondary to the increased risk of chromosomal abnormalities in these pregnancies. The increased risk of gestational diabetes and placenta previa may be secondary to the relationship between aging and progressive vascular endothelial damage resulting in reduced structural and functional health of placenta Cleary-Goldman et al. ${ }^{11}$ It has been suggested that increased biological ageing of the ovaries is a major factor for aneuploidy conditions in females -a 'limited oocytes pool' hypothesis

In comparison between cases with congenital anomalies and without regarding smoking we found that smoking increase risk of congenital anomalies, smoking with congenital anomaly cases $27(1.3 \%)$ while smoking without congenital anomaly represented $0.7 \%$. and there was highly statistically significant difference between both groups with $\mathrm{p}$ value 0.000 . our study in agreement with Shawky and Sadik ${ }^{8}$ that found statistically significant difference between cases which represented $55.44 \%$ and control $35 \%$ with OR 2.310 with p value <0.05. These defects are thought to be caused by carbon monoxide and nicotine. Carbon monoxide may reduce the oxygen supply of the body's tissues. Nicotine stimulates release of hormones that constrict the vessels of uterus and placenta so that less oxygen and fewer nutrients reach the fetus ${ }^{8}$.

In comparison between cases with congenital anomalies and without congenital anomalies regarding diabetes mellitus as a risk factor of congenital anomaly. We found that in cases with congenital anomaly maternal diabetes mellitus represent $(9.8 \%)$ versus $(6.0 \%)$ in cases without congenital anomaly and there was statistically significant difference between both groups with $\mathrm{p}$ value 0.000 . our study in agreement with 
Ordonez et al. ${ }^{13}$ whose study was review of the records of the Latin American Collaborative Study of Congenital Malformations (ECLAMC) at the University of Chile Clinical Hospital. A sample of 383 mothers with a chronic disease was compared with 297 healthy mothers. The presence of congenital malformations in the newborns was studied. And they found that Offspring of diabetic mothers had 8.95 times more probabilities of having a major malformation and 4.95 times more probabilities of having a minor defect.

In comparison according to DM our study disagree with Costa et al. ${ }^{14}$ whose study found no significant difference between both groups with $\mathrm{p}$ value 0.109 , OR 2.07 95\%CI (0.83-5.11). Abnormal maternal/fetal fuel metabolism, including hyperglycemia, hyperketonemia, and disordered metabolism of arachidonic acid, myoinositol, and prostaglandin, as well as increased oxidative stress have been shown to be responsible for some of the changes in embryonic high glucose levels during critical periods of morphogenesis appear to be the major teratogen in diabetic pregnancy. An additional possible mechanism is diabetes-induced hypoxia apparently, due to hyperglycemia 15 .

\section{CONCLUSION}

Our study provides further evidence suggesting a weak, but positive association between placenta previa and major congenital malformations, including all structural anomalies, chromosomal defects, and congenital hypothyroidisms, in the offspring. We found increased risk of congenital malformations among infants born to mothers who experienced placenta previa during pregnancy compared with their counterparts, by controlling several important confounders for the first time.

\section{REFERENCES}

1. Oyelese $Y$ and Smulian C. Placenta previa, placenta accreta, and vasa previa. Obstet Gynecol., 2006; 107:927

2. Oyelese $\mathrm{Y}$ and Canterino C. Placenta Previa and Placenta Accreta. In Bleeding During Pregnancy. Springer, New York, NY., 2011; p. 135-150.

3. Rosenberg T, Pariente G, Sergienko R, et al. Critical analysis of risk factors and outcome of placenta previa. Arch Gynecol Obstet., 2011; 284:47-51.

4. Usta M, Hobeika M, Musa A, et al. Placenta previaaccreta: risk factors and complications. Am J Obstet Gynecol., 2011; 193:1045-1049.

5. Salihu HM, Li Q, Rouse DJ, et al. Placenta previa: neonatal death after live births in the United States. Am J Obstet., 2003; 188(5):1305-9.

6. Kancherla V, Räisänen $S$, Gissler $M$, et al. Placenta previa and risk of major congenital malformations among singleton births in Finland. Birth Defects Res A Clin Mol Teratol., 2015; 193:527-535.

7. Cresswell JA, Ronsmans C, Calvert C, et al. Prevalence of placenta praevia by world region: a systematic review and meta-analysis. Trop Med Int Health., 2013; 18:712.

8. Shawky $M$ and Sadik I. Congenital malformations prevalent among Egyptian children and associated risk factors. Egyptian Journal of Medical Human Genetics, 2011; 12(1): 69-78.

9. Paul K, Wandabwa $\mathrm{J}$ and Doyle P. Risk factors for placenta previa presenting with severe vaginal bleeding in Mulago hospital, Kampala, Uganda. African Health Sciences, 2008; 8:445 -456.

10. Zlatnik G, Cheng W, Norton E, et al. Placenta previa and the risk of preterm delivery. The Journal of MaternalFetal \& Neonatal Medicine, 2007; 20(10), 719-723.

11. Cleary-Goldman J, Malone D, Vidaver J, et al. Impact of maternal age on obstetric outcome. Obstetrics \& Gynecology, 2005; 105(5): 983-990.

12. Parmar A, Rathod $P$, Patel V, et al. A study of congenital anomalies in newborn. NJIRM, 2010; 1(1): 13-17.

13. Ordonez $\mathrm{P}$, Nazer $\mathrm{J}$, Aguila $\mathrm{A}$, et al. Congenital malformations and chronic diseases of the mother. Latin American Collaborative Study of Congenital Malformations (ECLAMC) 1971-1999. Revista Medica de Chile, 2003; 131(4): 404-411.

14. Costa C, Gama S and Leal C. Congenital malformations in Rio de Janeiro, Brazil: prevalence and associated factors. Cadernos de saude Publica, 2006; 22: 24232431.

15. Ornoy A, Reece A, Pavlinkova G, et al. Effect of maternal diabetes on the embryo, fetus, and children: congenital anomalies, genetic and epigenetic changes and developmental outcomes. Birth Defects Research Part C: Embryo Today: Reviews, 2015; 105(1): 53-72. 